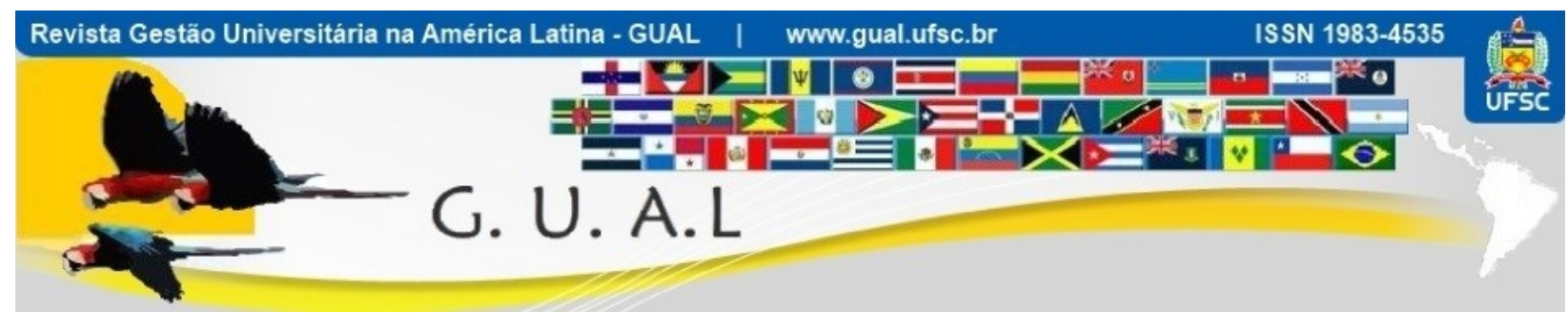

DOI: http://dx.doi.org/10.5007/1983-4535.2019v12n2p253

\title{
REDES SOCIAIS DE UM E DOIS MODOS: TRAJETÓRIA DA PRODUÇÃO CIENTÍFICA DO ENCONTRO DE ENSINO E PESQUISA EM ADMINISTRAÇÃO E CONTABILIDADE
}

\author{
SOCIAL NETWORKS OF ONE AND TWO MODES: TRAJECTORY OF THE \\ SCIENTIFIC PRODUCTION OF THE MEETING OF TEACHING AND RESEARCH \\ IN ADMINISTRATION AND ACCOUNTING
}

Henrique César Melo Ribeiro, Doutor

https://orcid.org/0000-0002-0704-1812 hcmribeirorevistas@gmail.com Universidade Federal do Piaú | Campus Ministro Reis Velloso Parnaíba | Piaúí | Brasil

Rosany Corrêa, Doutora https://orcid.org/0000-0002-2599-2742 rosanycorrea@hotmail.com Universidade Estadual do Piauí | Departamento de Ciência da Informação Teresina | Piauí | Brasil

Geovanna Karinna Magalhães Ribeiro, Graduanda https://orcid.org/0000-0003-1983-3101 geovannakarinna4@gmail.com Faculdade Maurício de Nassau | Campus Parnaíba Parnaíba | Piauí | Brasil

Recebido em 06/abril/2018

Aprovado em 19/fevereiro/2019

Publicado em 02/maio/2019

Sistema de Avaliação: Double Blind Review

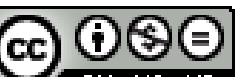

Esta obra está sob uma Licença Creative Commons Atribuição-Uso. 


\title{
RESUMO
}

O objetivo deste estudo foi analisar a trajetória da produção científica dos artigos divulgados no Encontro de Ensino e Pesquisa em Administração e Contabilidade durante os anos de 2007, 2009, 2011, 2013 e 2015. Metodologicamente, utilizou-se as técnicas de análise de redes sociais de um e dois modos em 520 artigos identificados. Na rede social one-mode das IES, com foco no degree, destacou-se a USP e a UFRGS. No que tange a rede social twomode (autores e IES), a USP novamente ficou em realce, seguida pelas instituições: UFU, UFSC, UFPE, UFMG, UFLA e UFBA. Ainda no que se refere a rede social de dois modos, agora, evidenciando os autores e temas, afloram-se os temas: casos de ensino, formação discente, ensino em administração, estratégias de aprendizagem, educação a distância, ensinoaprendizagem, pesquisa científica em administração, estratégia empresarial, pós-graduação stricto sensu em administração e competências acadêmicas. Conclui-se de maneira geral que, o presente estudo evidenciou, sob uma ótica diferente, a produção científica dos artigos evidenciados no EnEPQ, manifestando assim, dados, informações, conhecimentos e saberes contemporâneos sobre o referido congresso e, consequentemente sobre a referida área do saber, contribuindo para seu melhor entendimento e compreensão na literatura científica nacional.

Palavras-chave: Produção Científica. EnEPQ. Rede Social. One-Mode. Two-Mode.

\begin{abstract}
The objective of this study was to analyze the trajectory of the scientific production of articles published in the Meeting of Teaching and Research in Administration and Accounting during the years of 2007, 2009, 2011, 2013 and 2015. Methodologically, of social networks in one and two modes in 520 identified articles. In the one-mode social network of the HEIs, focusing on the degree, the USP and UFRGS stood out. Regarding the two-mode social network (authors and IES), USP was again highlighted, followed by institutions: UFU, UFSC, UFPE, UFMG, UFLA and UFBA. Still, with regard to social networking in two ways, now, highlighting the authors and themes, the following themes emerge: teaching cases, student training, teaching in administration, learning strategies, distance education, teaching-learning, research scientific management, business strategy, stricto sensu postgraduate in management and academic skills. It is generally concluded that the present study evidenced, from a different perspective, the scientific production of the articles evidenced in the EnEPQ, thus manifesting data, information, knowledge and contemporary knowledge about said congress and, consequently, on the said area of the knowledge, contributing to their better understanding and understanding in the national scientific literature.
\end{abstract}

Keywords: Scientific Production. EnEPQ. Social Network. One-Mode. Two-Mode. 


\section{INTRODUÇÃO}

Estudos que focam sobre a análise da produção científica de temas e ou áreas do conhecimento (FARIA; FIGUEIREDO, 2013), estão cada vez mais em evidência e destaque em termos mundiais, ocupando assim um lugar de realce em diversos meios de comunicação científicos (JABBOUR; SANTOS; BARBIERI, 2008), como, por exemplo, os eventos científicos, que são um importante fórum para discussão e troca de informações e saberes científicos entre pesquisadores, docentes, pós-graduandos de stricto sensu e ou lato sensu, graduandos e profissionais de outros setores produtivos (NASCENTES; KORN; ZANONI, 2017).

Ressalta-se o Encontro Nacional da Associação de Pós-Graduação em Administração (EnANPAD), que é considerado o evento científico de maior relevância da área de administração do Brasil (MIRANDA; CARVALHO; RAMOS, 2016), realizado desde 1976 pela Associação Nacional de Pós-Graduação e Pesquisa em Administração (ANPAD) (Quintella, 2003). Além do EnANPAD, existem outros eventos científicos, mas para este estudo, será enfatizado somente o Encontro de Ensino e Pesquisa em Administração e Contabilidade (EnEPQ) (BALSAN et al., 2016).

O EnEPQ é um espaço de discussão acadêmica de temas relevantes no âmbito do Ensino e Pesquisa em Administração e Contabilidade (EPAC), objetivando promover a interlocução entre pesquisadores dessa área do saber e, com isso, auxiliar no aperfeiçoamento da referida área do conhecimento no Brasil, observando, preferencialmente, os temas de interesse destacados, mediante a publicação, difusão e socialização de estudos científicos (ANPAD, 2018). Este estudo faz surgir a seguinte questão de pesquisa: qual a trajetória da produção científica dos artigos divulgados no EnEPQ durante os anos de 2007, 2009, 2011, 2013 e $2015 ?$

O objetivo do estudo é: analisar a trajetória da produção científica dos artigos divulgados no EnEPQ nos anos de 2007, 2009, 2011, 2013 e 2015. Justifica-se a realização desta pesquisa, em decorrência desta evidenciar informações contemporâneas sobre o campo do saber EPAC, à luz do evento científico EnEPQ mediante os artigos publicados por este nos anos de 2007, 2009, 2011, 2013 e 2015, sob a ótica da análise de rede sociais de um (GUIMARÃES et al., 2009; GUARIDO FILHO, E. R.; MACHADO-DA-SILVA; GONÇALVES, 2010) e dois modos (MACHADO JUNIOR et al., 2014; DEHDARIRAD; NASINI, 2017), enfocando a centralidade de grau (ALARCÃO; SACOMANO NETO, 2016), 
contribuindo com isso para melhor entendimento e compreensão desta área do conhecimento científico (ROSSONI; HOCAYEN-DA-SILVA, 2008).

É importante enfatizar que redes de um modo (unimodais), são as mais comuns na literatura acadêmica, enquanto que as redes de dois modos (bimodais), são menos comuns (LAVALLE; RODRIGUES; GREGHI, 2012), contribuindo, enriquecendo e justificando com maior relevo a realização deste estudo para o alargamento e aperfeiçoamento da literatura científica da área EPAC. Reitera-se que os dados mensurados e analisados, por meio dos indicadores de rede, contribuirão também para vislumbrar conhecimentos e saberes atuais de um campo do saber científico predominante nas divulgações do EnEPQ, sendo que estudos análogos a este, ou seja, que aferiram e mapearam todos os eventos do EnEPQ realizados até aqui, não foram localizados no âmbito cientifico nacional, robustecendo assim o ineditismo deste estudo.

Outra contribuição visível neste estudo é o uso da análise de redes de dois modos para mensuração e análise das informações, conhecimentos e saberes científicos da área EPAC no Brasil. Este panorama de análise é interessante, pois, versa uma ótica diferente e salutar de como os artigos publicados no EnEPQ se comportaram, proporcionando, por meio de uma visão diferente, um melhor entendimento e compreensão deste campo das Ciências da Administração e Contabilidade em conjunto no âmbito da análises de redes. Tais aferições poderão fornecer conhecimentos de como as redes 2-mode se interagem (TOMAÉL; MARTELETO, 2013), criando valor acadêmico para a área em análise.

\section{ENSINO E PESQUISA EM ADMINISTRAÇÃO E CONTABILIDADE}

A produção científica de artigos publicados sobre a área do conhecimento EPAC vêm evoluindo de maneira sistêmica nos meios de comunicação acadêmico nos últimos anos, especialmente, em eventos científicos como o caso do EnANPAD (COSTA; NOGUEIRA, 2016) e da Associação Nacional de Programas de Pós-Graduação em Ciências Contábeis Anpcont (RIBEIRO, 2017) fomentando, aperfeiçoando e difundindo as mencionadas áreas do saber no panorama acadêmico brasileiro.

Contudo, não é apenas em eventos científicos que a área do saber EPAC cresce. Isto posto, verifica-se que investigações nacionais sobre a produção científica de estudos divulgados sobre o campo acadêmico EPAC, têm sido publicadas em periódicos científicos de 
forma evolutiva e recorrente. Sendo assim, vislumbram-se a seguir, alguns dos resultados destes trabalhos científicos, com enfoque na análise de redes sociais.

Walter et al. (2009) analisaram os atores mais relevantes na evolução do campo de produção científica em ensino e pesquisa contábil no contexto brasileiro. Realçaram a USP como instituição mais central na rede de cooperação. Já no que se refere aos estudiosos, Accioly Júnior ficou em destaque, em decorrência do número de artigos publicados e por causa de sua centralidade de grau. Observaram também que um aspecto a ser aperfeiçoado consiste na cooperação com IES (Instituições de Ensino Superior) internacionais.

Freitas et al. (2012) mapearam por meio da análise de redes sociais, as interações colaborativas nos estudos desenvolvidos versando sobre Ensino e Pesquisa em Contabilidade. Contemplaram que Gilberto de Andrade Martins e Edgard Bruno Cornachione Jr., foram os estudiosos mais prolíficos; e que a USP foi responsável pelo maior número de publicações.

Ribeiro (2013) explorou a produção acadêmica da Revista de Educação e Pesquisa em Contabilidade de 2007 a 2012. Constatou que Aridelmo José Campanharo Teixeira e Gilberto de Andrade Martins foram os mais profícuos, sendo que o primeiro apresentou maior centralidade de grau. A USP foi a IES mais produtiva, se destacando também com instituição mais central, no que tange ao degree.

Costa e Nogueira (2016) descreveram o perfil das pesquisas e a evolução da área de EPAC nos artigos publicados nos anais do EnANPAD no período de 2001-2014. Demonstraram que a maioria dos artigos investigados abordam temas relativos ao ensinoaprendizagem em Administração e Contabilidade, e casos de ensino.

Ribeiro (2017) analisou a representação e as características da produção científica da temática educação e pesquisa em contabilidade publicada na Associação Nacional de Programas de Pós-Graduação em Ciências Contábeis de 2007 a 2016. Gilberto José Miranda, Edvalda Araújo Leal e Márcia Maria dos Santos Bortolocci Espejo foram os autores mais profícuos; USP, UFU e a FURB se destacaram como as IES mais produtivas. Houve uma alta centralidade de grau e de intermediação nas redes dos atores e uma baixa densidade.

Observa-se que esses estudos acadêmicos trazem para o panorama da administração e contabilidade (LARA et al., 2017) pensamentos, reflexões, insights, ideias acerca dos progressos da área do conhecimento EPAC sob a ótica das análise de redes sociais, expandindo o entendimento e a compreensão de suas potencialidades e limitações na academia. 
Entretanto, nenhum destes estudos, aprofundou o EnEPQ em todos os seus eventos ocorridos até aqui, mediante a análise de sua produção científica enfocando as redes sociais de um modo, e, especialmente as redes sociais de dois modos. Neste sentido, justificasse e reiterasse a importância deste estudo para a área em análise. E os resultados e contribuições evidenciadas neste estudo impactarão no desenvolvimento e difusão da referida área.

\section{PROCEDIMENTOS METODOLÓGICOS}

Entendendo que as conexões sociais entre os autores influenciam na criação, desenvolvimento, difusão e disseminação dos conhecimentos científicos (BARBOSA NETO; CUNHA, 2016). O objetivo deste estudo foi analisar a trajetória da produção científica dos artigos divulgados no EnEPQ durante os anos de 2007, 2009, 2011, 2013 e 2015. Com isso, utilizou-se para isso, a técnica de análise de rede social de um e de dois modos (RIBEIRO; SANTOS, 2017), para mensurar o fluxo de informação e conhecimento científico da referida rede (TOMAÉL; MARTELETO, 2006). É plausível afirmar que a estrutura da rede tem relação com os indicadores de produção científica (ROSSONI; HOCAYEN-DA-SILVA; FERREIRA JÚNIOR, 2008).

Salienta-se que uma rede social é formada por um conjunto de atores (nós da rede social) e suas respectivas conexões (SILVA et al., 2006). Sendo assim, a Análise de Redes Sociais (ARS) consiste na metodologia que permite o estudo das redes sociais pela análise, investigação, mapeamento e descrição das ligações entre os atores (TOMAÉL; MARTELETO, 2013), que nesta pesquisa consistirão nas autorias, autores, IES e temas. Isto posto, ressalva-se que as redes de dois modos abrangem as ligações entre dois conjuntos distintos de atores.

Versa-se que o termo "modo" refere-se a categorias específicas de atores. Já a rede social de um modo se caracteriza quando atores de uma rede têm interações com outros membros da mesma categoria - como uma rede de autores ou IES -, e rede de dois modos se caracteriza quando seus atores possuem ligações com membros de outras categorias. Então a rede social de dois modos pode ser concebida pela conexão entre autores e IES como um único sistema social, ou seja, em uma mesma rede social (TOMAÉL; MARTELETO, 2013).

Diante do evidenciado e para se conseguir responder a questão de pesquisa e alcançar o objetivo desejado, optou-se por estabelecer a rede two-mode entre os 520 estudos e as autorias; entre os 1.106 autores e as 135 IES; entre os 1.106 autores e os 142 temas. Ressalta- 
se que rede two-mode é uma matriz assimétrica, na qual cada célula determina o volume de ocorrências de compartilhamento em conjunto entre os 520 artigos e as autorias, entre os 1.106 pesquisadores e as 135 instituições, entre os 1.106 estudiosos e os 142 assuntos. Já a rede one-mode, isto é, de um modo, é uma matriz quadrada, na qual cada célula indica o volume de ocorrências de compartilhamento entre os autores e IES (GUARIDO FILHO; MACHADO-DA-SILVA; GONÇALVES, 2010; CRUZ et al., 2011; ROSSONI; GUARIDO FILHO, 2012).

É importante evidenciar que esta pesquisa enfatizará a centralidade como estrutura de rede (MELLO; CRUBELLATE; ROSSONI, 2010). Dentre as centralidades, a mais frequentemente usada é a centralidade de grau (Degree) (MENDES-DA-SILVA; ONUSIC; GIGLIO, 2013), que é calculada a partir do número de interações diretas que um ator possui com outro membro da rede social (CRUZ et al., 2011). Foi feita uma coleta de dados em artigos publicados nos anos de 2007, 2009, 2011, 2013 e 2015 do EnEPQ.

Os dados foram coletados no site da ANPAD (ANPAD, 2018). Reforça-se e reitera-se dizer que os estudos abrangidos nesta pesquisa científica foram especificamente do evento científico EnEPQ. Este procedimento possibilitou identificar 520 estudos publicados durante os períodos que foram realizados o evento EnEPQ. Foi realizada a análise dos dados mediante os seguintes indicadores de rede social de um e dois modos: (I) autoria; (II) rede dos autores; (III) rede das IES; (IV) rede two-mode (autores e IES); e (V) rede two-mode (autores e temas). Estes indicadores foram mensurados e capturados, usando os softwares UCINET 6 e NetDraw for Windows e Microsoft Excel 2007.

\section{ANÁLISE E DISCUSSÃO DOS RESULTADOS}

Esta seção manifestará a analise e a discussão dos resultados dos 520 artigos publicados no EnEPQ, sob a ótica das redes sociais de um e dois modos. A Figura 1 contempla a rede de dois modos (artigos publicados e autoria) (TOMAÉL; MARTELETO, 2013). Constata-se a predominância de estudos científicos em parceria, em especial com dois e três autores, ou seja, 171 e 163 publicações respectivamente. Resultado este corroborado na investigação de Ribeiro (2013). Mencionam-se também as publicações com quatro, um, cinco e seis pesquisadores com 86, 48, 37 e 15 trabalhos divulgados concomitantemente. 
Figura 1 Características de autoria

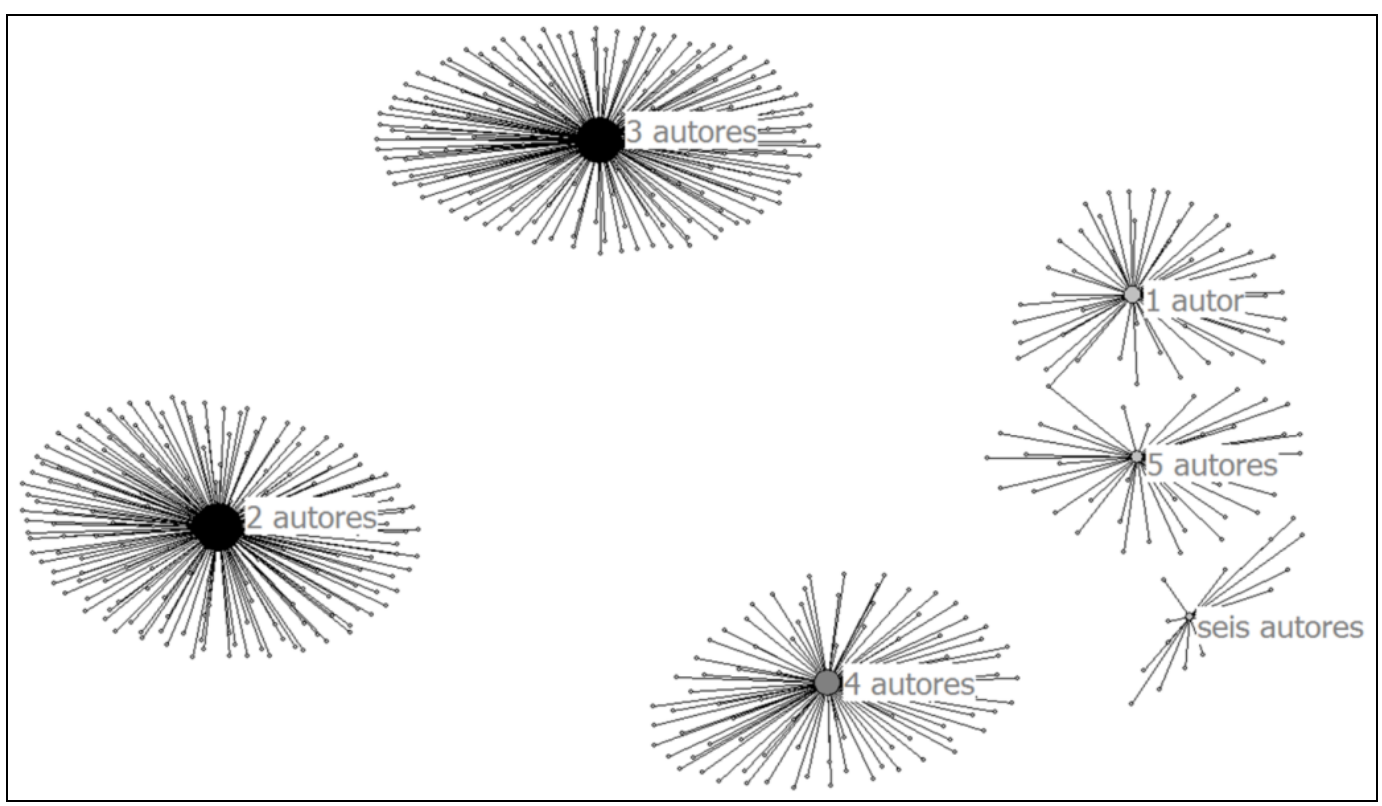

Fonte: Dados da pesquisa.

Em suma, entende-se que a quantidade de publicações em parceria refere-se ao número de pesquisadores/docentes que relacionaram como autores ou coautores, não levando em consideração o número de vezes em que ocorreram estas conexões (Figura 1). Com isso, compreende-se que o aumento do número de parcerias entre os estudiosos/professores, tende a maximizar o número de estudos publicados, influenciando diretamente nas colaborações nas redes sociais dos atores, ou seja, dos acadêmicos e de suas respectivas IES nativas (MELLO; CRUBELLATE; ROSSONI, 2010).

Mas é importante ressaltar que, a parceria nas publicações não está somente ligada aos pesquisadores/professores, mas também pode ser visualizada e medida por meio das cooperações dos discentes ou orientados com os professores ou orientadores respectivos (Figura 1), contribuindo diretamente para o crescimento, difusão, interdisciplinaridade, robustez e socialização de temas ou da área do conhecimento científico (SILVA et al., 2006), como é o caso do EPAC que este estudo se propôs a focar.

A Figura 2 visualiza a rede social de um modo dos 1.106 autores que publicaram estudos no EnEPQ, colocando em ênfase a centralidade de grau. Entende-se que a centralidade de grau é identificada pelo número de conexões diretas que um ator mantém em uma rede social, sendo que, quanto maior seu degree, maior será seu nível de comunicação na rede (TOMAÉL; MARTELETO, 2006), que aqui é vislumbrada pelos autores. 
Neste cenário, enfatizam-se os estudiosos: Gilberto José Miranda, Edvalda Araújo Leal, Victor Manoel Cunha de Almeida, Cléria Donizete da Silva Lourenço, Maria José Carvalho de Souza Domingues, Roberto Patrus, Kely César Martins de Paiva, Augusto Cézar de Aquino Cabral, Cintia Rodrigues de Oliveira Medeiros, Maria Naiula Monteiro Pessoa e João Paulo de Brito Nascimento. Ribeiro (2017) corrobora com as informações desta seção, sobretudo no que se refere aos acadêmicos Gilberto José Miranda, Edvalda Araújo Leal realçando-os como os mais centrais em sua pesquisa.

Figura 2 Rede de coautoria (degree)

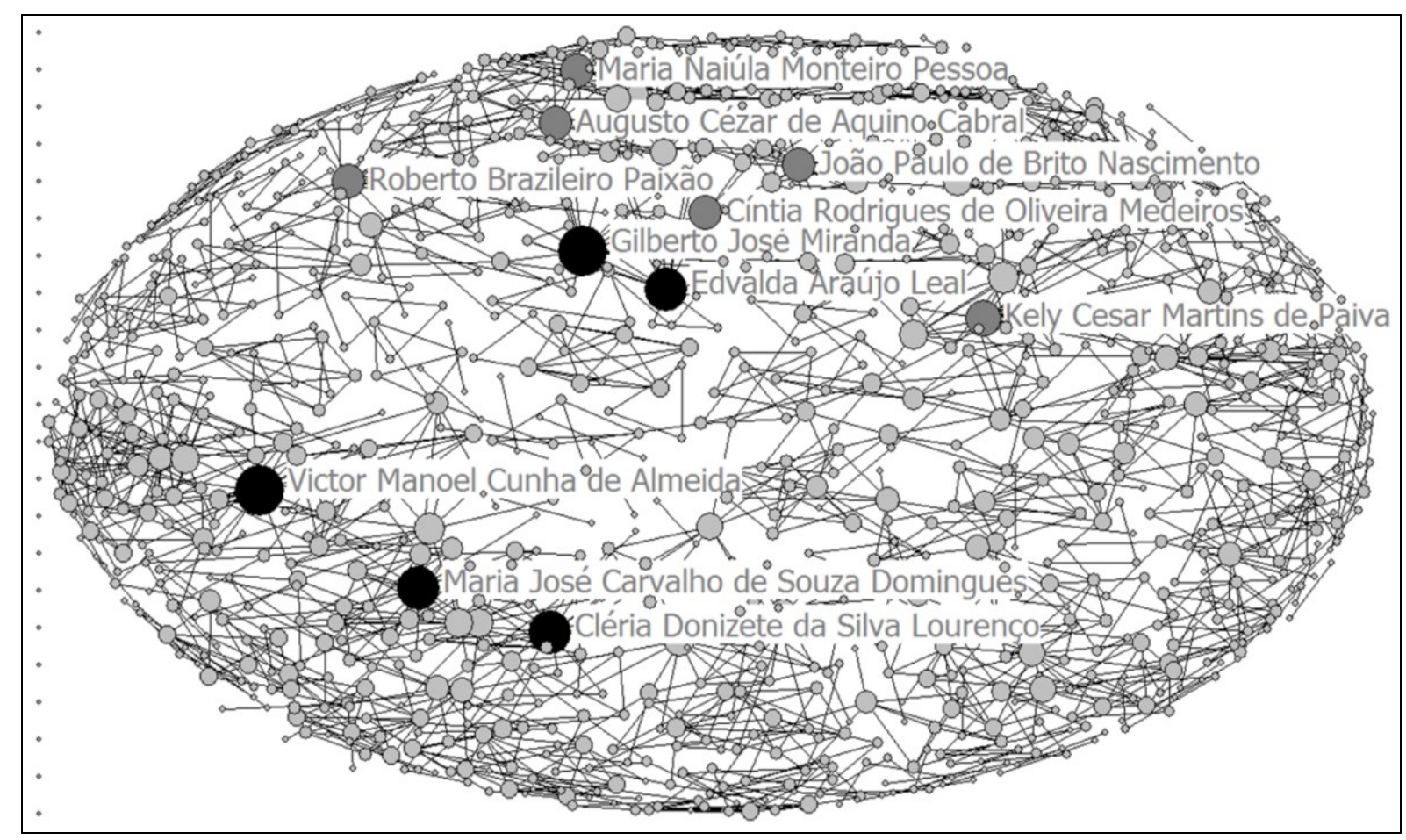

Fonte: Dados da pesquisa.

Salienta-se que, dentre os nove pesquisadores mais profícuos desta pesquisa: Gilberto José Miranda, Roberto Patrus, Anielson Barbosa da Silva Edvalda Araújo Leal, Roberto Brazileiro Paixão, Victor Manoel Cunha de Almeida, Amelia Silveira, Kely César Martins de Paiva e Tania Maria Diederichs Fischer, cinco estão entre os que tiveram e se destacaram com maior degree (Figura 2). Entendendo-se com isso que, os cinco pesquisadores em destaque são os mais relevantes desta investigação (BARBOSA NETO; CUNHA, 2016).

Tal fato pode ser em virtude de que, quanto maior os relacionamentos de coautoria promovidos com outros estudiosos, maior o número de artigos publicados pelos atores (Freitas et al., 2012). Os achados desta seção, contribuem para manifestar quais acadêmicos 
são os mais importantes para a produção científica dos estudos publicados no EnEPQ sobre o campo do conhecimento EPAC. Reitera-se e reforça-se a preponderância e a contribuição desta seção ao vislumbrar não somente os autores mais centrais deste estudo, mais também, evidenciar que alguns além de ficarem em relevo no degree, ficaram em realce na proficuidade (Rossoni \& Hocayen-da-Silva, 2008), tornando-os relevantes para a área ora analisada.

A Figura 3 contempla a rede das 135 IES, realçando a centralidade de grau. Visualizase um grande grupo de instituições que apresentam um forte tipo de colaboração entre si, porém, com os outros cinco grupos restantes, tal conexão não se verifica, o que expõe e manifesta o isolamento de tais grupos de instituições com o conjunto de IES principal desta pesquisa. Estruturalmente, os cinco grupos de instituições isoladas estão em posição periférica no campo do saber ora analisado, não compartilhando laços de pesquisa com as instituições mais centrais, (que estão no maior grupo em destaque nesta seção), tanto em termos estruturais, quanto em termos de volume de produção de artigos, quanto também no que tange as informações e saberes científicos (ROSSONI; HOCAYEN-DA-SILVA; FERREIRA JÚNIOR, 2008).

Neste cenário, versa-se que IES mais centrais tendem a ser cada vez mais centrais, acarretando, na maior parte dos casos, maior hierarquização destas IES na rede social (MELLO; CRUBELLATE; ROSSONI, 2010). Neste contexto evidenciam-se as IES mais centrais deste trabalho: USP, UFRGS, FURB, UFMG, UFPE, UFLA, UFBA e UFSC.

Figura 3 Rede Social das IES (degree)

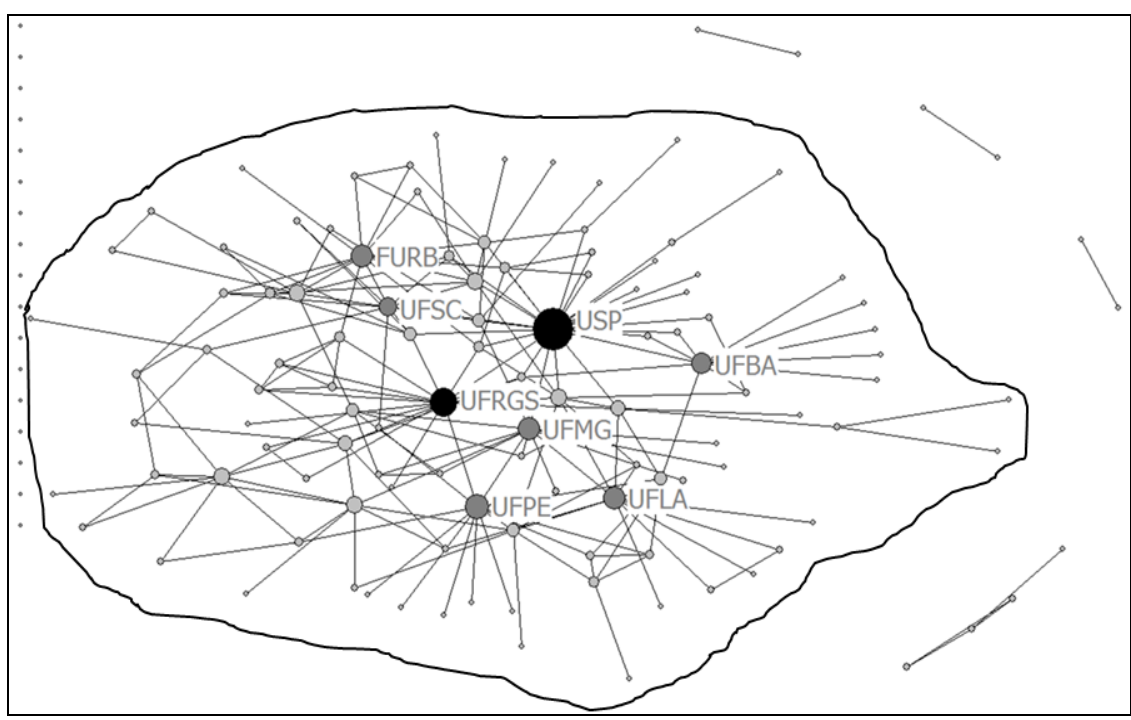

Fonte: Dados da pesquisa. 


\section{REDES SOCIAIS DE UM E DOIS MODOS: TRAJETÓRIA DA PRODUÇÃO CIENTÍFICA DO ENCONTRO \\ DE ENSINO E PESQUISA EM ADMINISTRAÇÃO E CONTABILIDADE \\ DOI: http://dx.doi.org/10.5007/1983-4535.2019v12n2p253}

Salienta-se que, destas oito IES, seis estão entre as nove instituições mais profícuas desta investigação. Neste panorama, é possível afirmar que, as IES que conseguiram seu destaque tanto na produção acadêmica, como também na centralidade de grau, são as mais proeminentes (MELLO; CRUBELLATE; ROSSONI, 2010) deste estudo.

Diante do fato, é factível empreender que, esta seção contribui de maneira robusta e decisiva para contemplar os nomes das instituições mais relevantes para a produção acadêmica das publicações sobre a área do conhecimento EPAC sob a ótica do EnEPQ. Em publicações similares a esta, os trabalhos científicos de Walter et al. (2009), Freitas et al. (2012), Ribeiro (2013) e Ribeiro (2017) corroboram com os achados desta seção, em especial no que se refere a relevância e importância da USP para a área.

A Figura 4 evidencia a elaboração de uma rede 2-mode entre atores e afiliações (ROSSONI; GRAEML, 2009), ou seja, uma relação entre os 1.106 autores e as 135 IES desta pesquisa, colocando em relevo as IES que têm mais pesquisadores vinculados a estas. Neste painel vislumbram-se as IES: USP, UFU, UFPE, UFMG, UFSC, UFLA e UFBA como as que tiveram o maior número de pesquisadores vinculados a elas durante a realização dos eventos bienais do EnEPQ, ficando com maior ênfase em comparação com as outras instituições mencionadas na Figura 4.

É importante ressalvar que, destas instituições com realce nesta seção, seis ficaram também em destaque como as mais centrais deste trabalho (Figura 3), e até entre as nove mais profícuas, foram elas: USP, UFPE, UFMG, UFSC, UFLA e UFBA. Sendo assim, e sob a ótica do EnEPQ, não é ansioso e nem temeroso afirmar que tais instituições são as mais importantes e salientes no enfoque da produção científica de artigos sobre a área do saber EPAC no âmbito acadêmico brasileiro.

O realce destas IES são provavelmente por ocorrência de grupos de estudos enfocados na criação e surgimento de pesquisas relacionadas a área ora em análise, contribuindo e influenciando simultaneamente no aparecimento, na maturação, no alargamento ou até mesmo na concretização de temas que compõem de maneira macro o bojo e as nuances que fazem do campo do saber EPAC um dos mais manifestados, divulgados e socializados em eventos e revistas científicas das Ciências da Administração e da Contabilidade no meio acadêmico nacional. Sabendo que redes bimodais referem-se à conexão entre dois conjuntos diferentes de atores (LAVALLE; RODRIGUES; GREGHI, 2012), como por exemplo: pesquisadores e temas/áreas do conhecimento (TOMAÉL; MARTELETO, 2013). 
Figura 4 Rede Social two-mode (autores e IES)

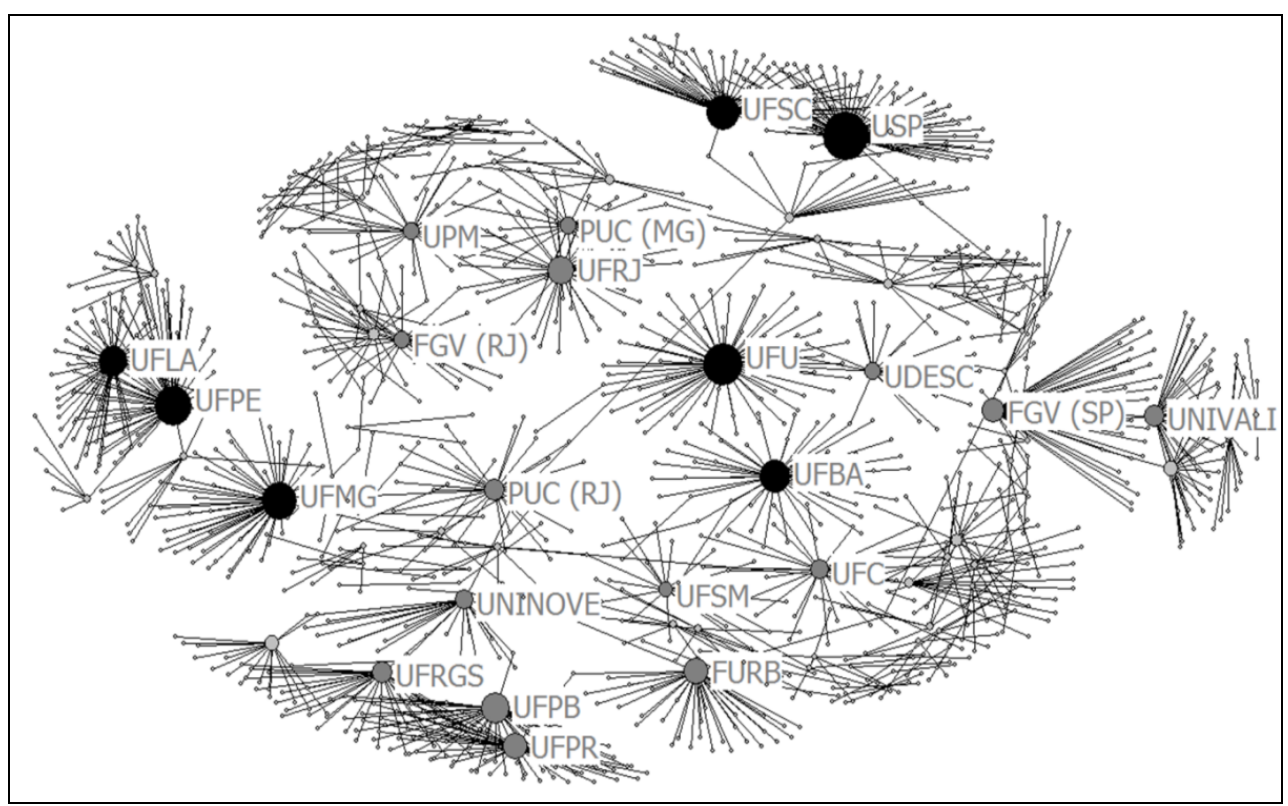

Fonte: Dados da pesquisa.

A Figura 5 ressalta a rede de dois modos dos autores e temas. A temática Caso de ensino foi a que teve mais pesquisadores publicando sobre ela, impactando diretamente em seu destaque na produção acadêmica de artigos no EnEPQ. Sua ênfase, pode ser explicada em decorrência de sua proliferação nos cursos de pós-graduação stricto sensu nas áreas de Administração (Faria \& Figueiredo, 2013) e Contabilidade (LARA et al., 2017) no Brasil. Outro possível impacto de seu crescimento em estudos científicos é em virtude da ANPAD desde 2007 publicar casos de ensino nos anais de seu congresso e no EnEPQ (FARIA; FIGUEIREDO, 2013; ANPAD, 2018).

O tema Formação discente ficou em realce na Figura 5, mostrando que muitos acadêmicos se envolvem a divulgação deste tema no EnEPQ. Tal iniciativa impactou em sua proficuidade no referido evento. Seu relevo nesta pesquisa está relacionado com o seu processo de aquisição de conhecimentos teóricos, técnicos e operacionais, através das IES (MAIA; CARVALHO-FREITAS, 2015), e, que por meio de seus cursos de graduação ou pósgraduação capacitam o aluno para o mercado de trabalho (MOTTA; QUINTELLA, 2012).

Outro assunto que manifestou interesse dos estudiosos por sua produção, impactando de maneira direta em seu realce como um dos temas mais produzidos do EnEPQ foi a Educação a distância. Neste contexto salienta-se que a educação a distância se revela como uma estratégia de aprendizagem (ABBAD; CORREAA; MENESES, 2010) significativa e com forte tendência na esfera educacional, sobretudo na educação superior. Isto posto, ainda que 
seja um tema novo na academia, vem evoluindo nas publicações em periódicos e eventos científicos, sobretudo no EnANPAD e EnEPQ (SILVA; MELO; MUYLDER, 2015).

Ressalva-se a seguir a temática Estratégias de aprendizagem, que, além de se destacar como um dos assuntos que teve mais autores manifestando interesse em publica-lo, também ficou entre os temas mais prolíferos no EnEPQ. Seu enfoque é entendido, pois, as estratégias de aprendizagem são recursos utilizados no habitual do docente, a fim de buscar garantir aos discentes escolhas que auxiliem no atingimento dos objetivos de ensino-aprendizagem postos nos cursos de graduação ou pós-graduação nas IES (COSTA; PFEUTI; CASA NOVA, 2014). Aproveita-se para contemplar o tema Ensino-aprendizagem, que, como ocorrerá com os anteriores, ficou em destacado nessa seção, e, como assunto mais publicado no EnEPQ.

Figura 5 Rede Social two-mode (autores e temas)

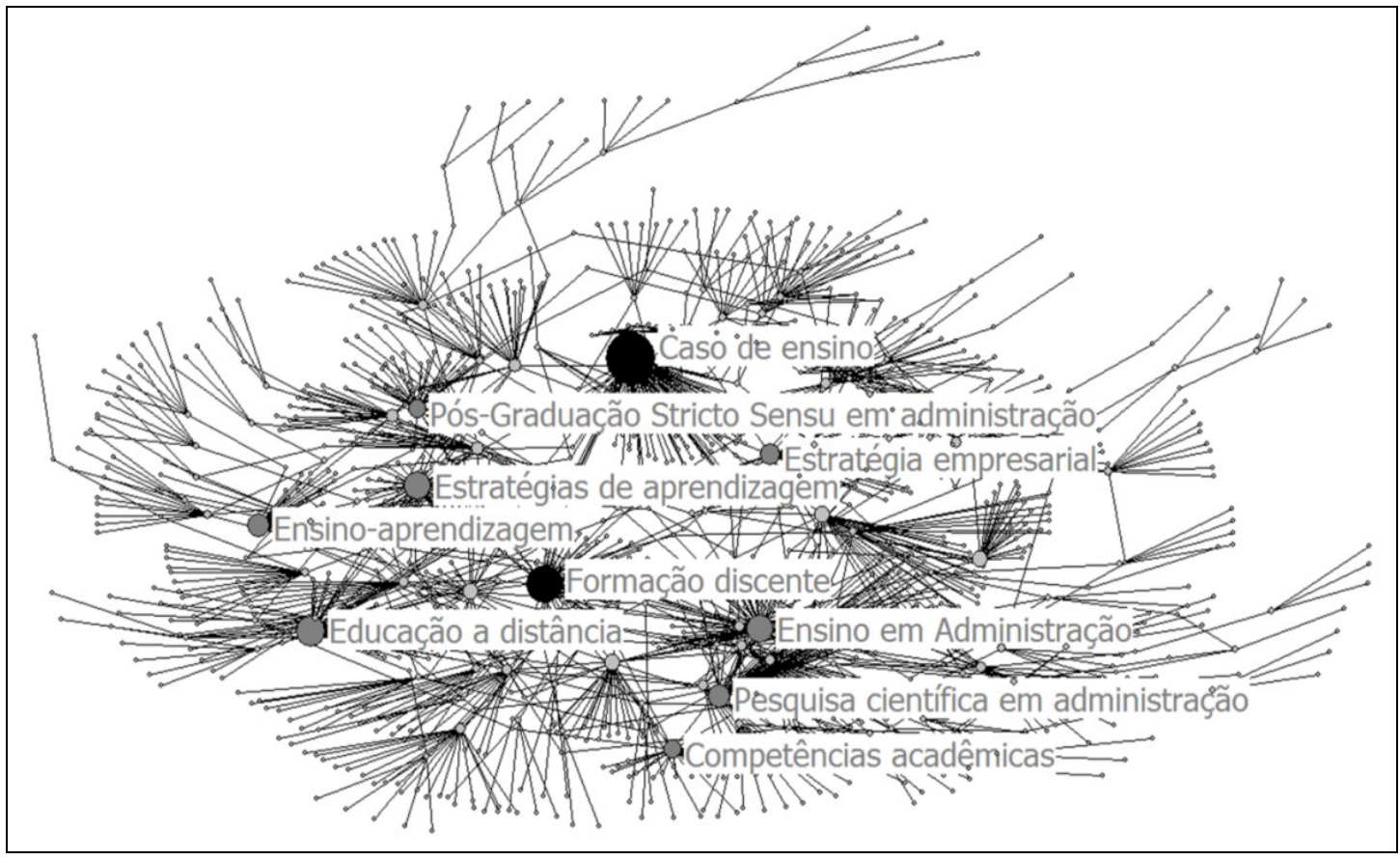

Fonte: Dados da pesquisa.

Vislumbram-se também as temáticas Ensino em administração, Pesquisa científica em administração e Pós-Graduação stricto sensu em Administração. Suas respectivas ênfases como assuntos que chamam a atenção dos acadêmicos em publica-los, fazendo-os ficar entre os temas mais produzidos no EnEPQ está diretamente relacionado ao escopo e foco do referido evento científico (ANPAD, 2018), mas também, por entender e compreender que todos são de suma importância para o alargamento, aperfeiçoamento, difusão e socialização do conhecimento em ensino e pesquisa em administração stricto sensu, impactando 
fortemente na robustez no campo do saber acadêmico Administração (GUIMARÃES et al., 2009).

Ainda cabe referenciar os temas Estratégia empresarial e Competências acadêmicas, que também ficaram entre os assuntos mais divulgados pelos pesquisadores no EnEPQ. Os achados contemplados nesta seção, apontam os assuntos que mais manifestam interesse pelos estudiosos da área em análise, influenciando, na maioria das vezes em sua proeminência e proficuidade nas publicações acadêmicas no evento científico objeto de estudo.

Resultados evidenciados aqui, contribuem para demonstrar quais temáticas os autores se manifestam e se vinculam mais a publicar no campo do conhecimento EPAC, à luz do EnEPQ, derivando com isso na possibilidade de criação de novos trabalhos, e, consequentemente no surgimento de novos temas, ou no aperfeiçoamento ou maturação de outros na literatura científica da área.

\section{CONSIDERAÇÕES FINAIS}

Foi analisada a trajetória da produção científica dos artigos divulgados do EnEPQ durante os anos de 2007, 2009, 2011, 2013 e 2015, mediante as técnicas de análise de redes sociais de um e dois modos em 520 artigos. Conclui-se que os dados, indicadores e informações contemporâneas evidenciadas nesta pesquisa, contribuíram para preencher possíveis gaps sobre a área do conhecimento EPAC, sob a ótica do EnEPQ.

Os conhecimentos aferidos aqui tem como papel, passar aos leitores, docentes, discentes, pesquisadores juniores ou seniores a importância que a mencionada área tem para as Ciências da Administração e Contabilidade respectivamente, identificando, aferindo, visualizando, manifestando informações e saberes que colaborarão para o desenvolvimento de mais trabalhos científicos na área; contribuirão para ampliar e fazer surgir novos grupos de estudos nesse campo científico; e fomentando os laços nas redes de coautoria e das IES, tanto no 1-mode como no 2-mode, impactando em suas maiores densidades.

Como limitação, esta investigação se deparou em analisar a produção científica somente de um evento específico da ANPAD, o EnEPQ, entretanto, tanto a questão de pesquisa, como também o objetivo do trabalho foram respondido e alcançado respectivamente, com muito afinco, esforço, vontade e criatividade, utilizando-se de técnicas de redes 1-mode e 2-mode. Porém, é sabido que nenhuma pesquisa científica está totalmente acabada, e sempre necessitará de aperfeiçoamento; e, buscando também replicar o saber e o 
desenvolvimento da área em análise, sugere-se para estudos futuros, ampliar a investigação, mediante mensurações comparativas com outros eventos análogos ao que foi trabalhado aqui, no âmbito nacional e também no panorama internacional. Tal iniciativa, alargará e robustecerá as informações contempladas nesta pesquisa, replicando o conhecimento, e, auxiliando no fomento e evolução de publicações sobre o EPAC.

\section{REFERÊNCIAS}

ABBAD, G. DA S.; CORRÊA, V. P.; MENESES, P. P. M. Avaliação de treinamentos a distância: relações entre estratégias de aprendizagem e satisfação com o treinamento. Revista de Administração Mackenzie, v. 11, n. 2, p. 43-67, 2010.

ALARCÃO, A.L.M.; SACOMANO NETO, M. Actor centrality in network projects and scientific performance: an exploratory study. Revista de Administração e Inovação, v. 13, n. 2 , p. $78-88,2016$.

BALSAN, L.A.G.; KNEIPP, J. M.; TONIN, S.; COSTA, V. M. F. Os vínculos que o indivíduo estabelece com a organização: uma análise da produção científica brasileira. Revista de Ciências da Administração, v. 18, n. 45, p. 25-37, 2016.

BARBOSA NETO, J. E.; CUNHA, J. V. A. da. Colaboração acadêmica em bancas de mestrado na pós-graduação stricto sensu em contabilidade. Contabilidade, Gestão e Governança, v. 19, n. 1, p. 126-145, 2016.

COSTA, R. S. de; NOGUEIRA, D. P. Perfil e evolução do ENANPAD: Análise bibliométrica e sociométrica da área de ensino e pesquisa em administração e contabilidade de 2001 a 2014. Revista Espacios, v. 37, n. 21, p. 20-31, 2016.

COSTA, S. A. da; PFEUTI, M. de L. M.; CASA NOVA, S. P. de C. As estratégias de ensinoaprendizagem utilizadas pelos docentes e sua relação com o envolvimento dos alunos.

Revista Evidenciação Contábil \& Finanças, v. 2, n. 1, p. 59-74, 2014.

CRUZ, A. P. C. da; ESPEJO, M. M. dos S. B.; COSTA, F.; ALMEIDA, L. B. de. Perfil das redes de cooperação científica: congresso USP de controladoria e contabilidade-2001 a 2009. Revista Contabilidade \& Finanças, v. 22, n. 55, p. 64-87, 2011.

DEHDARIRAD, T.; NASINI, S. Research impact in co-authorship networks: a two-mode analysis. Journal of Informetrics, v. 13, n. 2, p. 371-388, 2017.

ENSINO E PESQUISA EM ADMINISTRAÇÃO E CONTABILIDADE (EnEPQ). Apresentação. Disponível em: <http://www.anpad.org.br>. Acesso em: 10 jan. 2018.

FARIA, M.; FIGUEIREDO, K. F. Casos de ensino no Brasil: análise bibliométrica e orientações para autores. Revista de Administração Contemporânea, v. 17, n. 2, p. 176197, 2013. 
FREITAS, E. M.; PACHECO, V.; KAROLKIEVICZ, R. M.; SILLAS, E. P. Cooperação acadêmica: análise de publicações em eventos científicos sobre ensino e pesquisa em contabilidade. Revista de Educação e Pesquisa em Contabilidade, v. 6, n. 4, p. 399-418. 2012.

GUARIDO FILHO, E. R.; MACHADO-DA-SILVA, C. L.; GONÇALVES, S. A. Organizational institutionalism in the academic field in Brazil: social dynamics and networks. Revista de Administração Contemporânea, v. spe, n. 6, p. 149-172, 2010.

GUIMARÃES, T. de A.; GOMES, A. de O.; ODELIUS, C. C.; ZANCAN, C.; CORRADI, A. A. A Rede de programas de pós-graduação em administração no Brasil: análise de relações acadêmicas e atributos de programas. Revista de Administração Contemporânea, v. 13, n. 4, p. 564-582, 2009.

JABBOUR, C. J. C.; SANTOS, F. C. A.; BARBIERI, J. C. Gestão ambiental empresarial: um levantamento da Produção científica brasileira divulgada em periódicos da área de administração entre 1996 e 2005. Revista de Administração Contemporânea, v. 12, n. 3, p. 689-715, 2008.

LARA, F. L.; SILVA, M. C. da; COSTA, F.; MORAES, N. M. Panorama das publicações nacionais de caso de ensino na área de contabilidade e administração. XXIV Congresso Brasileiro de Custos, Anais eletrônicos..., 2017.

LAVALLE, A. G.; RODRIGUES, M.; GREGHI, T. An outside view: councils in brazilian structure of participatory governance. Anais eletrônicos... II Forum da ISA, 2012.

MACHADO JUNIOR, C.; SOUZA, M. T. S. A. de; PARISOTTO, I. R. dos S. Institucionalização do conhecimento em sustentabilidade ambiental pelos programas de pósgraduação stricto sensu em administração. Revista de Administração Contemporânea, v. 18 , n. 6, p. 854-873, 2014.

MAIA, A. M. de C.; CARVALHO-FREITAS, M. N. de. O trabalhador com deficiência na organização: um estudo sobre o treinamento e desenvolvimento e a adequação das condições de trabalho. Revista Eletrônica de Administração, v. 21, n. 3, p. 689-719, 2015.

MELLO, C. M. de; CRUBELLATE, J. M.; ROSSONI, L. Dinâmica de relacionamento e prováveis respostas estratégicas de programas brasileiros de pós-graduação em administração à avaliação da Capes: proposições institucionais a partir da análise de redes de co-autorias.

Revista de Administração Contemporânea, v. 14, n. 3, p. 434-457, 2010.

MENDES-DA-SILVA, W.; ONUSIC, L. M.; GIGLIO, E. M. Rede de pesquisadores de finanças no Brasil: um mundo pequeno feito por poucos. Revista de Administração Contemporânea, v. 17, n. 6, p. 739-763, 2013.

MIRANDA, A. C. C. de; CARVALHO, A. V.; RAMOS, A. S. M. Comunicação científica em Administração. Revista Ciências Administrativas, v. 22, n. 2, p. 573-604, 2016. 
MOTTA, G. DA S.; QUINTELLA, R. H. A utilização de jogos e simulações de empresas nos cursos de graduação em administração no estado da Bahia. Revista Eletrônica de Administração, v. 18, n. 2, p. 317-338, 2012.

NASCENTES, C. C.; KORN, M. das G. A.; ZANONI, M. V. B. Química analítica no Brasil: atualidades, tendências e desafios. Química Nova, v. 40, n. 6, p. 643-649, 2017.

QUINTELLA, R. H. Encontro nacional da Anpad x meeting of AOM: lições, questionamentos e especulações. Revista de Administração de Empresas, v. 43, n. 2, p. 107-115, 2003.

RIBEIRO, H. C. M. Características da Produção Veiculada na Revista de Educação e Pesquisa em Contabilidade no Período de 2007 a 2012. Revista de Educação e Pesquisa em Contabilidade, v. 7, n. 4, p. 424-443, 2013.

RIBEIRO, H. C. M. Dez anos da produção científica da área temática educação e pesquisa em contabilidade publicada na AnpCONT. Revista Mineira de Contabilidade, v. 18, n. 3, p. 65$78,2017$.

RIBEIRO, H. C. M.; SANTOS, M. C. dos. Artigos bibliometricos: produção acadêmica divulgada nos periódicos nacionais sob a ótica da análise de rede social. Revista Gestão Universitária na América Latina, v. 10, n. 1, p. 229-248, 2017.

ROSSONI, L.; GRAEML, A. A Influência da imersão institucional e regional na cooperação entre pesquisadores no Brasil. Redes - Revista Hispana para el Análisis de Redes Sociales, v. 16, n. 9 , p. $228-249,2009$.

ROSSONI, L.; GUARIDO FILHO, E. R. Onipresença nos conselhos editoriais: prestígio e cerimonialismo na atividade científica redes. Redes - Revista Hispana para el Análisis de Redes Sociales, v. 22, n. 8, p. 189-218, 2012.

ROSSONI, L.; HOCAYEN-DA-SILVA, A. J. Cooperação entre pesquisadores da área de administração da informação: evidências estruturais de fragmentação das relações no campo científico. Revista de Administração da USP, v. 43, n. 2, p. 138-151, 2008.

ROSSONI, L.; HOCAYEN-DA-SILVA, A. J.; FERREIRA JÚNIOR, I. Aspectos estruturais da cooperação entre pesquisadores no campo de administração pública e gestão social: análise das redes entre instituições no Brasil. Revista de Administração Pública, v. 42, 6, p. 1041 1067, 2008.

SILVA, A. B. de O. e; MATHEUS, R. F.; PARREIRAS, F. S.; PARREIRAS, T. A. S. Análise de redes sociais como metodologia de apoio para a discussão da interdisciplinaridade na ciência da informação. Ciência da Informação, v. 35, n. 1, p. 72-93, 2006.

SILVA, M. P. D.; MELO, M. C. de O. L.; MUYLDER, C. F. de. Educação a distância em foco: um estudo sobre a produção científica brasileira. Revista de Administração Mackenzie, v. 16, n. 4, p. 202-230, 2015. 
TOMAÉL, M. I.; MARTELETO, R. M. Redes sociais de dois modos: aspectos conceituais. TransInformação, v. 25, n. 3, p. 245-253, 2013.

TOMAÉL, M. I.; MARTELETO, R. M. Redes sociais: posições dos atores no fluxo da informação. Revista Eletrônica de Biblioteconomia e Ciência da Informação, n. spe 1, p. 75-91, 2006.

WALTER, S. A.; CRUZ, A. P. C. da; ESPEJO, M. M. dos S. B.; GASSNER, F. P. Uma análise da evolução do campo de ensino e pesquisa em contabilidade sob a perspectiva de redes. Revista Universo Contábil, v. 5, n. 4, p. 76-93, 2009. 